\title{
EVALUATION OF THE FOURTH VENTRICLES OF ADULTS IN NORTH-EASTERN NIGERIANS USING COMPUTERIZE TOMOGRAPHIC IMAGES
}

\author{
${ }^{1}$ Amaza DS, ${ }^{2}$ Zirahei JV, ${ }^{3}$ Sambo N, ${ }^{1}$ OyewaleAA, ${ }^{1}$ Kogi GA \\ ${ }^{1}$ Department of Human Anatomy, Faculty of Basic Medical Sciences, College of Medicine, \\ Kaduna State University, Kaduna State, Nigeria. ${ }^{2}$ Department of Human Anatomy, \\ Faculty of Basic Medical Sciences, College of Medical Sciences, University of Maiduguri, Borno \\ State, Nigeria. ${ }^{3}$ Department of Human Physiology, Faculty of Basic Medical Sciences, \\ College of Medical Sciences, Baze University, Abuja, Nigeria. \\ Correspondences and reprint request to: Dr. D. S. Amaza. Department of Human Anatomy, \\ Faculty of Basic Medical Sciences, College of Medicine, Kaduna State University, \\ Kaduna State, Nigeria. \\ Email: drdanladisambo@gmail.com | Phone: 07035585716
}

\begin{abstract}
Background: Knowledge of anatomy of the fourth ventricle and the structures around it, is significant in sex determination, surgical operations and brain disorders. Accurate measurements of the fourth ventricle are needful in evaluating brain disorders and in decision making before any neurosurgical procedures. Objective: To determine the dimensions of the apparently normal fourth ventricles and compare the parameters among males and females with a view to providing baseline data. Method: Retrospective study was carried out on brain CT images. Six hundred (600) brain CT images of adult North-eastern Nigerians (350 males and 250 females) were measured. The age range for the individuals was 18-75years. The brain CT images for males and females were classified separately into six (6) age groups spanned eight (8) years interval. Measurements were done using Dicomworks software. The software provides a meter rule with which measurements were done, based on a standard method. Greatest height of fourth ventricle was measured from the roof and floor of the fourth ventricle while the width measured at the midpoint of the ventricle. Results: The height of the fourth ventricle was larger in males $(9.95 \mathrm{~mm} \pm 1.04)$ as compared to females $(8.38 \mathrm{~mm} \pm 1.69)$. The width of the fourth ventricle was also observed to be greater in males $(12.95 \mathrm{~mm} \pm 1.29)$ than in females (11.67 $\mathrm{mm} \pm 1.45)$. Thus, the difference between the lengths and widths of the fourth ventricles were higher and statistically significant $(\mathrm{p}<0.05)$ among males and females. Conclusion: The present study concludes that the parameters of the $4^{\text {th }}$ ventricle measured were sexually dimorphic and can be used in sex determination in the sample population. This study also has provided reference point for the normal values of the length and width of the fourth ventricle in male and female Nigerians.
\end{abstract}

Keywords: Assessment, CT Images, Fourth ventricles, Morphometry, North-Eastern Nigerians.

\section{INTRODUCTION}

The fourth ventricle is a diamond shaped structure in anterior view but triangular shaped in lateral cross-sectional view, located in the midline cavity. ${ }^{1}$ It communicates superiorly with the third ventricle

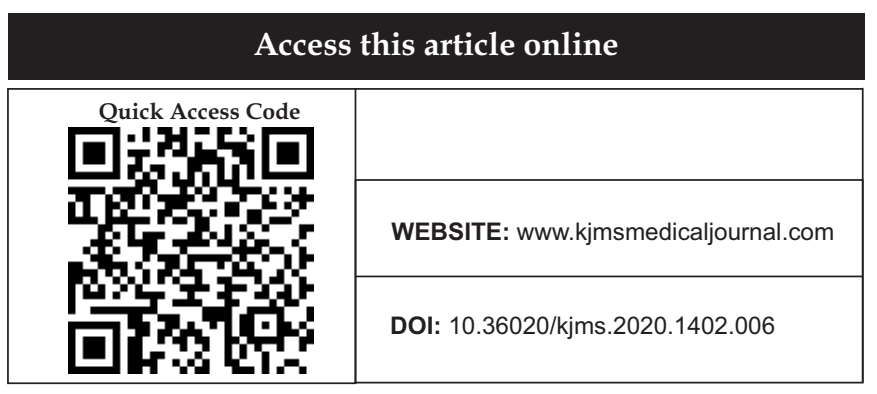

by the cerebral aqueduct and anteroinferiorly with the central canal of the medulla oblongata. In the midline and laterally it communicates with the cisterna magna (cerebellomedullaris) by the foramen of Magendie and Luschka respectively. ${ }^{1,2}$

As human brain ages, characteristic structural changes occur that are considered normal and expected. ${ }^{3}$ Study by ${ }^{3}$ suggested as ageing occur the brain undergoes many gross and histopathologic changes with regression of the brain tissue leading to the enlargement of the ventricles. 
Computed Tomography (CT) has provided revolutionary means for morphologic study of the brain in vivo. Majority of CT studies suggests that diencephalon volume is reduced and the volume of the third ventricle is enlarged with physiologic ageing. ${ }^{4}$ According to studies, ${ }^{5,6} \& 7$ modern computerized tomography allows easy and safe non-invasive study of the ventricular system, without complications.

Understanding the normal and abnormal anatomy of the ventricular system of brain is helpful for clinicians, neurosurgeons, and radiologists in day-to-day clinical practice. ${ }^{4}$ The cerebral ventricular system is a marker of brain development and a predictor of neurodevelopment outcome.

Morphometric analysis of cerebral ventricular system is important for evaluating changes due to growth, ageing, intrinsic and extrinsic pathologies. ${ }^{4}$ Morphometric analysis of brain structures such as volume, shape and size of ventricular system recently has become a main focus of interest in studies of some neuropsychiatric diseases like schizophrenia and Alzheimer's disease. ${ }^{9}$

Knowledge of anatomy of cerebral ventricular system is important for endoscopic neurosurgery. ${ }^{10}$ Morphometric analysis of ventricular system is also helpful in the diagnosis and classification of hydrocephalus and in assessment, follow-up of enlargement of ventricular system during therapy ventricular shunts. ${ }^{11}$

Therefore, the aim of this study was to analyse the dimension of the fourth ventricle in both males and females, and also to determine changes in fourth ventricular size with respect to age among the north eastern Nigerians.

\section{MATERIALS AND METHOD}

This retrospective study was carried out on six hundred (600) brain Computed Tomographic (CT) images of adult North-eastern Nigerians (350 males and 250 females) with age ranged from 1875 years. The CT images for males and females were classified separately into six (6) age groups spanned eight (8) years interval. These CT images were obtained by purposive sampling technique from the archive in the workstation of the Radiology Department, University of Maiduguri
Teaching Hospital (UMTH) in Borno State, Nigeria. The CT images were selected randomly which had no history of head injury, local mass lesion, hydrocephalus or previous intra-cranial surgery. The CT scanner used in the study was "Siemens somatom volume zoom 16 slice multi detector spiral CT scanner" with a scan time of 1-10 sec and slice thickness of $4 \mathrm{~mm}$ (Model No.227892HM7 and manufactured by General Electronic (GE), Chicago, USA).

\section{Exclusion criteria:}

Images of patients below 18 or above 75 years of age were not included in this study. Poorly produced CT images were also exempted from the study.

Index for sexual dimorphism (ISD) was used to assess whether the parameters measured were sexually dimorphic. ISD was calculated thus:

ISD $=\underline{\text { males' mean value }} \times 100$

Females' mean value

ISD is expressed as a percentage and a value greater than $100 \%$ indicates sexual dimorphism while value less than $100 \%$ is considered not sexually dimorphic. ${ }^{12}$

Measurement of fourth ventricle was made by using dicomworks software. Two (2) parameters were measured as height and width in $\mathrm{cm}$ which were converted to the nearest $\mathrm{mm}$.

1. Greatest height of fourth ventricle was measured from the upper margin of the Pons to the lower limit of open part of medulla oblongata as points a-bto the nearest $\mathrm{mm}$ (Fig 1).

2. Greatest width of fourth ventricle was the distance between roof and floor of the fourth ventricle indicated as points $a-b$ to the nearest $\mathrm{mm}$ (Fig 1$)$. 


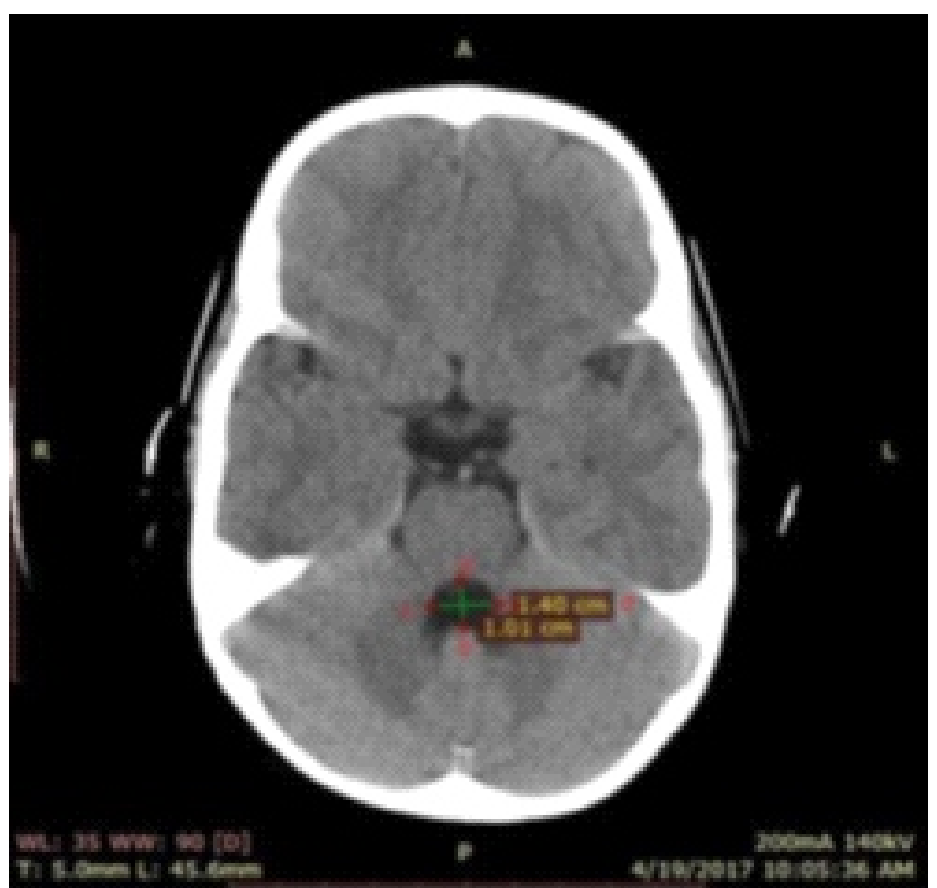

Fig 1: CT Image at the level of fourth ventricle in male showing a-b as the height of fourth ventricle recorded as ventricular height $(\mathrm{VH})$ in $\mathrm{cm}$ and converted to the nearest $\mathrm{mm}$ while $\mathrm{c}-\mathrm{d}$ as width of fourth ventricle recorded as ventricular width (VW) in $\mathrm{cm}$ and converted to the nearest mm adopted from. ${ }^{13}$

\section{Statistical Analysis}

Data obtained from the measurements were subjected to statistical analyses. The means, Standard deviation and standard error of the mean of were calculated. One way ANOVA with Dunnett's post-hoc test was performed using GraphPad InStat version 3.00 for window 95 (http://www.graphpad.com was done where a probability level of $\mathrm{P}<0.001$ was considered extremely significant, $p<0.01$ very significant, $\mathrm{p}<0.05$ significant, while probability level of $\mathrm{P}>0.05$ was considered not significant.

\section{RESULTS}

This study was carried out among 600 patients (350 males and 250 females) in the age group studied. The height of the fourth ventricle was larger in males $(9.95 \mathrm{~mm} \pm 1.04)$ as compared to females $(8.38 \mathrm{~mm} \pm 1.69)$, which was not significant $(p>0.001)$. The width of the fourth ventricle was also observed to be greater in males $(12.95 \mathrm{~mm} \pm 1.29)$ than in females $(11.67 \mathrm{~mm} \pm 1.45)$, the difference is not significance $(p>0.001)$. The maximum height $(13.90 \mathrm{~mm})$ in males and $(11.90 \mathrm{~mm})$ in females, were seen in the age range of $58-75 y$ years and 42 - 49years respectively. The Least height recorded was $(8.90 \mathrm{~mm})$ in males and $(8.3 \mathrm{~mm})$ in females. The greatest width recorded was $(17.28 \mathrm{~mm})$ for males and $(16.77 \mathrm{~mm})$ for females, while the least width was $(9.35 \mathrm{~mm})$ males and $(5.65 \mathrm{~mm})$ females.

Table 1: Dimensions of the Fourth Ventricles in males and females

\begin{tabular}{lllclc}
\hline Parameters & \multicolumn{5}{c}{$\begin{array}{c}\text { Gender } \\
\text { Males }(\mathrm{n}=350)\end{array}$} \\
& $\begin{array}{l}\text { Females }(\mathrm{n}=250) \\
\text { Total }(\mathrm{n}=600)\end{array}$ & T-Value & P-Value \\
Ventricular Height & $9.95 \pm 1.04$ & $8.16 \pm 1.23$ & $8.65 \pm 1.14$ & 4.55 & 0.001 \\
Ventricular Width & $12.95 \pm 1.29$ & $11.67 \pm 1.61$ & $11.98 \pm 1.45$ & 5.25 & 0.001 \\
\hline
\end{tabular}

Values are mean \pm Standard Deviation. Values in parentheses are $p$-values at $p<=0.001$

Table 2 showed demarking points for the mean male and the mean female for $\mathrm{VH}$ were $9.95 \mathrm{~mm}$ and $8.16 \mathrm{~mm}$ respectively, while at VW the demarking point for male and female were $12.95 \mathrm{~mm}$ and $11.67 \mathrm{~mm}$ respectively. Indexes for sexual dimorphism for VHand VW were, 121.9 and 111.0 respectively. Index of sexual dimorphism (ISD) was found to be greater than 100 in all the parameters measure; this showed that male had higher values over female counterparts. 
Table 2: Demarking Point and Index of Sexual Dimorphism for Ventricular Height and Ventricular Width for Male and Female.

\begin{tabular}{|c|c|c|c|c|c|c|c|}
\hline \multirow[b]{2}{*}{ Parameters } & \multicolumn{2}{|c|}{ MALE } & \multicolumn{3}{|c|}{ FEMALE } & \multirow[b]{2}{*}{ D.P } & \multirow[b]{2}{*}{ ISD } \\
\hline & $\begin{array}{l}\text { Mean } \pm S D \\
\text { of V.H }\end{array}$ & $\begin{array}{l}\text { Calculated } \\
\text { Range }\end{array}$ & D.P & $\begin{array}{l}\text { Mean } \pm S D \\
\text { of V.W }\end{array}$ & $\begin{array}{l}\text { Calculated } \\
\text { Range }\end{array}$ & & \\
\hline $\mathrm{VH}$ & $9.95 \pm 1.04$ & $6.87-13.11$ & $>11.85$ & $8.16 \pm 1.23$ & $4.47-11.85$ & $<6.87$ & 121.9 \\
\hline VW & $12.95 \pm 1.29$ & $9.08-16.82$ & $>16.50$ & $11.67 \pm 1.61$ & $6.84-16.50$ & $<9.08$ & 111.0 \\
\hline
\end{tabular}

VH=Ventricular Height; VW= Ventricular Width; S.D = Standard Deviation; ISD= Index of Sexual Dimorphism \&D. P =Demarking Point

Tables 3 and 4 shows descriptive statistics of the two parameters (VH and VW) with respect to age groups. There are gradual but steady increase in mean vales from the least age group (18-25 years) to the highest age group ( $58-75$ years) showing significant statistical difference $(p<0.05)$ in all but age groups $50-57$ and 58-75 years respectively. The least and the highest $\mathrm{VH}$ are $9.6 \mathrm{~mm}$ and $9.8 \mathrm{~mm}$ at age groups $18-25$ and $50-$ 57 years respectively. While the least and the highest VW are $12.6 \mathrm{~mm}$ and $13.9 \mathrm{~mm}$ at age groups 18-25 and $42-49$ years respectively.

Table 3: Descriptive Statistic for Ventricular Height (VH) in Both Sexes.

\begin{tabular}{llllll}
\hline \multicolumn{4}{c}{ MALE } & \multicolumn{2}{c}{ FEMALE } \\
\hline $\begin{array}{l}\text { AGE GP } \\
\text { (in yrs) }\end{array}$ & $\begin{array}{l}\text { Mean } \pm \text { S. D } \\
\text { VH (in mm) }\end{array}$ & $\begin{array}{l}\text { 95\% CL } \\
\text { (in mm) }\end{array}$ & $\begin{array}{l}\text { Mean } \pm \text { VH D } \\
\text { (in mm) }\end{array}$ & $\begin{array}{l}95 \% \text { CL } \\
\text { (in mm) }\end{array}$ & P-VALUE \\
$26-33$ & $9.6 \pm 1.3$ & $9.1-10.1$ & $8.3 \pm 1.4$ & $7.7-8.7$ & P $<0.01$ \\
$34-41$ & $9.5 \pm 1.0$ & $9.2-9.8$ & $8.4 \pm 1.4$ & $8.0-8.8$ & $\mathrm{P}<0.05$ \\
$42-49$ & $9.6 \pm 1.8$ & $9.1-10.1$ & $8.4 \pm 1.2$ & $7.9-8.8$ & $\mathrm{P}<0.01$ \\
$50-57$ & $9.3 \pm 1.3$ & $8.9-9.8$ & $8.3 \pm 1.4$ & $7.7-8.9$ & $\mathrm{P}<0.01$ \\
$58-75$ & $9.8 \pm 1.0$ & $8.4-9.2$ & $8.5 \pm 1.0$ & $8.0-9.0$ & NS \\
\hline
\end{tabular}

S.D=Standard Deviation V.H=Ventricular Height S.E=Standard Error

95\% CONF=95\% Confidence LimitP value=significance between male and female

Table 4: Descriptive Statistic for Ventricular Weight (VW) in Both Sexes.

\begin{tabular}{llllll}
\hline \multicolumn{5}{c}{ MALE } & \multicolumn{5}{c}{ FEMALE } \\
\hline AGE GP & Mean \pm S. D & $95 \%$ CL & Mean \pm S. D & $95 \%$ CL & P VALUE \\
(in yrs) & VW (in mm) & (in mm) & VW (in mm) & (in mm) & \\
$18-25$ & $12.6 \pm 1.6$ & $12.0-13.2$ & $11.6 \pm 1.1$ & $11.5-12.2$ & P $<0.01$ \\
$26-33$ & $13.1 \pm 1.1$ & $12.7-13.5$ & $12.2 \pm 1.6$ & $11.7-12.6$ & $\mathrm{P}<0.01$ \\
$34-41$ & $13.3 \pm 1.1$ & $12.9-13.6$ & $12.3 \pm 1.6$ & $11.8-12.9$ & $\mathrm{P}<0.001$ \\
$42-49$ & $13.9 \pm 1.2$ & $12.9-13.8$ & $12.9 \pm 1.0$ & $12.5-13.4$ & $\mathrm{P}<0.01$ \\
$50-57$ & $13.6 \pm 1.3$ & $13.0-14.0$ & $12.2 \pm 1.1$ & 11.712 .7 & $\mathrm{P}<0.01$ \\
$58-75$ & $13.8 \pm 0.9$ & $13.4-14.3$ & $11.9 \pm 1.0$ & $11.5-12.2$ & $\mathrm{P}<0.001$ \\
\hline
\end{tabular}

S.D=Standard Deviation, V.W=Ventricular Weight, S.E= Standard Error

95\% CONF=95\% Confidence LimitP value=significance between male and female 


\section{DISCUSSION}

The Human nervous system is the most complex, widely investigated and yet poorly understood physical system. ${ }^{14}$ Evaluation of the normal measurements of the cerebral ventricles in the living human has great importance in the diagnosis and monitoring of several pathologies. ${ }^{15}$ The height of the fourth ventricle was larger in males $(9.95 \mathrm{~mm} \pm 1.04)$ as compared to females $(8.38 \mathrm{~mm} \pm 1.69)$, which was not significant ( $p>0.001)$. The width of the fourth ventricle was also observed to be greater in males $(12.95 \mathrm{~mm}$ $\pm 1.29)$ than in females $(11.67 \mathrm{~mm} \pm 1.45)$, the difference is not significance $(p>0.001)$. The maximum height $(13.90 \mathrm{~mm})$ in males and $(11.90$ $\mathrm{mm}$ ) in females, were seen in the age range of 58 75 years and $42-49$ years respectively. The Least height recorded was $(8.90 \mathrm{~mm})$ in males and $(8.3$ $\mathrm{mm}$ ) in females. The greatest width recorded was $(17.28 \mathrm{~mm})$ for males and $(16.77 \mathrm{~mm})$ for females, while the least width was $(9.35 \mathrm{~mm})$ males and $(5.65 \mathrm{~mm})$ females.

This study is similar to study, ${ }^{13}$ which showed the height of the fourth ventricle was larger in males $(9.95 \mathrm{~mm} \pm 1.04)$ with respect to females' counterparts $(8.38 \mathrm{~mm} \pm 1.69)$, which was not significant $(p>0.001)$. The width of the fourth ventricle on the other hand was also observed to be greater in males $(12.95 \mathrm{~mm} \pm 1.29)$ compared to females $(11.67 \mathrm{~mm} \pm 1.45)$.

Studies ${ }^{16}$ revealed that the height of the fourth ventricle was larger in males $(10.15 \mathrm{~mm})$ compared to females $(8.38 \mathrm{~mm})$, which was not significant $(p>0.05)$. The width of the fourth ventricle was also was greater in males $(13.23 \mathrm{~mm})$ than in females $(12.17 \mathrm{~mm})$. ${ }^{17}$ Reported the height of the fourth ventricle to be
greater in males $(11.8 \mathrm{~mm})$, than in females
$(11.1 \mathrm{~mm})$. The width of the fourth ventricle was
found to be greater than the height in both gender
and was more in males ( $13.1 \pm 2.3 \mathrm{~mm})$ than in
females $(12.1 \pm 2.4 \mathrm{~mm})$.

Studies revealed that brain regression involving both the cerebrum and the cerebellum usually begins by the seventh decade and thereafter accelerated with advancing age. ${ }^{18,19,20}$ Hence the reason for increase in dimensions of the parameters in the lower decades as observed in the present study.

In the present study the Indexes for sexual dimorphism for VH and VW were, 121.9 and 111.0 respectively. Index of sexual dimorphism (ISD) was found to be greater than 100 in all the parameters measure; this showed that male had higher values over female counterparts. This result supports that $\mathrm{VH}$ and VW are sexually dimorphic in the sample population hence can be used for sex determination.

In the present study, there are gradual but steady increase in mean values from the least age group (18-25 years) to the highest age group (58-75 years) showing significant statistical difference $(p<0.05)$ in all but age groups 50-57 and 58-75 years respectively. The least and the highest $\mathrm{VH}$ are $9.6 \mathrm{~mm}$ and $9.8 \mathrm{~mm}$ at age groups $18-25$ and $50-57$ years respectively. While the least and the highest VW are $12.6 \mathrm{~mm}$ and $13.9 \mathrm{~mm}$ at age groups $18-25$ and $42-49$ years respectively.

\section{CONCLUSION}

This study generated baseline data on the fourth ventricle and indicated that there were significance differences between the fourth ventricle (height and width) of males and females $(p<0.001)$. The heights and the widths of the fourth ventricle are significantly higher $(p=<0.001)$ in males than in the female counterparts. ISD showed that $\mathrm{VH}$ and VW are sexually dimorphic because their values are more than 100, hence can be used for sex determination in the sample population. There are also increases in all ventricular parameters, with increase in age which was most profound in the older age groups.

\section{RECOMMENDATION}

This study confirms that morphometric assessment of the fourth ventricle is 
population- specific. Studies on sex determination using demarking points and multi-variant analysis is hereby recommended, in addition to this study, replication in the southern part of Nigeria so as to give a better picture of the racial variation which exists in Nigerian population.

\section{Acknowledgements}

I gratefully acknowledge the ethical committee of University of Maiduguri Teaching Hospital (UMTH) for their kind approval that lead to the success of this study and also to the management Staff of Radiology Department for screening and selection of the CT images of the brain.

\section{REFERENCES}

1. Singh V. Study of anatomy of the fourth ventricle. Textbook of Clinical Neuroanatomy Elsevier. 2010; 137:120123.

2. Snell RS. The ventricular system of the brain. Clinical neuroanatomy. 2006; 6:440461.

3. Schochet SS. Neuropathology of ageing. $\mathrm{Neurology} \mathrm{clinic}$ of $\mathrm{North}$ Amsterdam.1988;16 (3):569-580.

4. Campbell Clark, Randy Marbeck, David Li. An empirical model for analyzing and interpreting ventricular measures; Journal of Neurology, Neurosurgery, and Psychiatry 1990:53:411-415.

5. Fox JH, Huckman MS, and Topel JL. The use of Computerised tomography in senile dementia. Journal of Neurology Neurosurgery and Psychiatry, 1975; 38: 948-953.

6. Huckman MS, Fox J, and Topel J. The validity of criteria for the evaluation of cerebral atrophy by Computarised tomography. Radiology, 1975; 116: 85-92.

7. Lee SH, and Krishna CUG. Computerised tomography and Magnetic Resonance Imaging. McGraw-Hill, New York.1987.

8. Burton $P$, Drayer MD. Imaging of the aging brain; Radiology; volume 1988; 166:785793.

9. Coffey CE, Wilkinson WE, Parashos IA.1992 Quantitative cerebral anatomy of the aging human brain: a cross-sectional study using magnetic resonance imaging. Neurology; 1992; 42:

10. Condon B, Grant R, Hadley D, Lawrence A. 1988. Brain and intracranial cavity volumes: in vivo determination by MRI. Acta Neurol Scand.1988; 78:387-393.
11. Gawler J, du Boulay GH, Bull JWD, Marshall J. Computerized tomography (the EMI scanner): a c o m p a r i s o $n$ w i $h$ pneumoencephalography and ventniculography. J Neurol Neurosurg Psychiatry; 1976; 39:203211.

12. Marin Vodanic, Jelena Dumancic, Zeljko Demo and Dair Mihelic. Determination of Sex by Discriminant Function Analysis of Mandible from two Croatian Archeological Sites. Acta Stonatol Croat, 2006; 40(3):263-277.

13. Singh A; Singh A. K. and Singh, $\mathrm{H}$. Morphometric study of fourth ventricle indices in normal subjects by computed tomography. International Journal of Multidisciplinary Research and Development; 2017; 4:10; 135-139.

14. Williams PL, Bannister LH, Berry MM, Collins P, Dyson M. Grays Anatomy. Churchill Livingstone. 1999; 38:486490.

15. Brijraj S, Ujwal G. Ventricle of brain: Morphometric studies by computerized tomography scan. International Journal of medical research and health sciences. 2014; International Journal of Multidisciplinary Research and Development 139;3(2):381-387.

16. Usman J.D. Cephalometric assessment of fourth ventricles by using computerized tomography scan. Nigerian Journal of Basic and Applied Science. 2012; 20(3):208-212.

17. Medora DC, Natekar PE. Morphometric study of the ventricular 
system of brain by Computerised tomography: Jour. Anat. Soc. India. 2007; 56(1):19-24.

18. Ellis RJ. Norms for some structural changes in the human cerebellum from birth to old age. Journal Comparative Neurology, 1920;32:1-33.

19. Barron SA, Jacobs L. and Kinkel WR. Change in size of normal lateral ventricles during ageing determined by Computerised Tomography. Neurology. 1976; 26:11-1013.

20. Dekaban AS, and Sadowsky D. Changes in brain weight during the span of human life: Relation of brain weight to body height and body weight. Annals of Neurology 1978; 4: 345-356.

Cite this article as: Amaza DS, Zirahei JV, Sambo N, OyewaleAA, Kogi GA. Evaluation of The Fourth Ventricles of Adults in North-Eastern Nigerians Using Computerize Tomographic Images. KJMS 2020; 14(2): 140 - 146. 